\title{
How do Lawyers Engineer and Develop LegalTech Projects? A Story of Opportunities, Platforms, Creative Rationalities, and Strategies
}

\author{
Christophe Dubois \\ University of Liege, Belgium
}

\begin{abstract}
Over the last 15 years, the working context of lawyers has undergone many changes. Evolving in an increasingly competitive, deregulated, and globalized market, they are subject to higher tax pressure while being exposed to unbridled technological innovation. Indeed, a growing number of entrepreneurs are using digital solutions to provide online legal services that are supposed to be faster and cheaper. If many of them are nonlawyer legal entrepreneurs, many lawyers are also engineering innovative projects and launching their own start-up companies, known as "LegalTech" or "LawTech." However, few studies - or none to our limited knowledge - provide an empirically grounded analysis of such projects, leaving some questions unanswered. Who are these entrepreneurial lawyers? How and why do they engineer and develop LegalTech projects? How do they challenge the legal profession? To answer these questions, this article draws on a qualitative study of three contrasted start-ups Belgian lawyers have recently developed. The research methodology combines gray and scientific literature reviews, webdocument (hereafter "manifestos") analysis, and semi-directive interviews led with the start-up's founders $(n=5)$, the Bar Association's representatives $(n=3)$, and some members of the main Belgian LegalTech network $(n=4)$.
\end{abstract}

Keywords: LegalTech; projects; lawyers; profession; organization; strategies.

\section{Introduction and Context of the Study}

In the last few years, academics, legal professionals, and consultants have published many books, reports, and articles about LegalTech, LawTech, and e-Law. ${ }^{1}$ In this paper, the neologism of LegalTech is preferred to other synonyms, as it designates the combination of preexisting legal services (e.g., connecting with legal professionals, assisting with legal drafting, supporting business processes, information management, etc.) and digital technologies, such as machine learning, automated language processing, blockchain, legal research analysis, quantification and visualization of forensic hazards, as well as chatbots. If this notion is often used as a noun in the plural form - "LegalTechs"- referring to heterogeneous things such as platforms, startups, software or applications, it is used here as an adjective qualifying some concrete projects that aim to provide legal services through automated processing. Drawing on an empirical in-depth study and on a project-based analytical framework, this article analyzes the serendipitous beginnings of three small projects engineered by young Belgian lawyers, the challenges they have been facing, and the strategies they have been adopting in their complex contexts of action.

Many publications tend to map and categorize the new services offered by the companies active in this emerging field. ${ }^{2}$ The Stanford School Center for Legal Informatics provides an interesting and influential map on its CodeX ${ }^{3}$ website, which distinguishes between nine categories of LegalTech services pertaining to marketplace, document automation, practice management, legal research, legal education, online dispute resolution, e-discovery, analytics, and compliance. Indeed, these projects attract considerable financial investments. According to Pivovarov, ${ }^{4}$ the global investments in LegalTech amounted to

\footnotetext{
${ }^{1}$ Many references are cited below. As for the reports, see Institut Montaigne (2017) and Thomson Reuters (2019).

${ }^{2}$ Two typical examples are Chishti, The LegalTech Book; and Corrales Compagnucci, "Tomorrow's Lawyer Today?"

${ }^{3}$ Stanford Law School, "CodeX Techindex."

${ }^{4}$ Pivovarov, "713\% Growth."
} 
USD \$224 million in 2016, USD\$233 million in 2017, and USD\$1,663 million in 2018. These elements obscure the fact that many LegalTech entrepreneurs are small-scale lawyers, as indicated by recent mapping conducted in Belgium. ${ }^{5}$ This article focuses on their concrete projects, mainly for two reasons.

The first is that there is a lack of empirical analysis conducted on LegalTech projects. As a consequence, these start-ups are a priori considered as either a threat ${ }^{6}$ or a promise ${ }^{7}$ for legal professionals in general, and for lawyers' profession in particular. Many publications share at least four ungrounded postulates. First, they posit a digital revolution and consider the present situation in terms of a break between an archaic past and a transformed (utopian or dystopian) future. Second, they assume that this revolution is being driven by the individual initiative of LegalTech entrepreneurs. ${ }^{8}$ No longer would they be expecting anything from traditional institutions, but rather rely on technology and on their individual creativity to optimize their organizational processes, increase their efficiency, shine on the market, and become the heroes of their own history. Third, these authors consider an ideal legal market in which technology spontaneously meets the aspirations of professional actors and the expectations of their clients. ${ }^{9}$ Fourth, echoing the popular fascination for robots and artificial intelligence, they adopt the tone of technological determinism, ${ }^{10}$ postulating that the use of digital technologies is a necessity for every economic agent. Presented as the "one best way" to survive in competitive and disrupted markets, these technologies are perceived as autonomous and independent from the social context in which they emerge. Considering that these publications lack empirical evidence and postulate a unidirectional influence exercised by digital technology on professions, this article aims to provide some empirical account of the mutual influences between these technologies and lawyers' professional practices, knowledge, ${ }^{11}$ and regulation bodies.

The second reason why this article focuses on these projects is that entrepreneurial lawyers are understudied. While many publications consider the use and adoption of LegalTech by big law firms, ${ }^{12}$ professional service firms, ${ }^{13}$ and even small and medium-sized traditional legal firms, ${ }^{14}$ rarer — or absent - are those analyzing how LegalTech projects are being engineered in these working contexts. Is it due to the fact that, according to some authors, small and private practitioners are less prone than big law firms to in-house innovation, ${ }^{15}$ while "sophisticated technology may be costly for a small organisation"? ${ }^{16}$ For these reasons, this article proposes analyzing how and why some young, under 40-year-old lawyers are investing reasonable amounts of money — or time, if no money is available - in the engineering of LegalTech projects. ${ }^{17}$

While the roots and heart of LegalTech are in the United States (US), its development in Europe generates lower investments. However, among the 1,294 LegalTech projects listed worldwide in $2020,{ }^{18} 249$ were located in the United Kingdom and 231 in France. ${ }^{1920}$ Most French projects are less than four years old and have been initiated by one or two lawyers. The Paris Bar has set up an incubator ${ }^{21}$ aiming "to encourage lawyers to seize the opportunities offered by digital technologies and to become entrepreneurs." 22 In Belgium, 80 LegalTech projects were listed in $2019^{23}$ and classified in 10 categories: practice management, knowledge research, news management, matchmaking platforms, online dispute resolution, online legal services, document management, corporate management, and legal design. The French- and Dutch-speaking wings of the Belgian Bar Association have also been organizing annual LegalTech conferences. ${ }^{2425}$ Like its Parisian counterpart, the French-speaking wing has set up an incubator, ${ }^{26}$ which organizes an annual Innovation Awards ceremony and grants innovation prizes to creative projects in

\footnotetext{
${ }^{5}$ van Wassenhove, Livre Blanc Guide.

${ }^{6}$ Susskind, Tomorrow's Lawyers; Susskind, The End of Lawyers; Bosman, Death of a Law Firm.

${ }^{7}$ Kobayashi, "Law's Information Revolution as Procedural Reform"; Ribstein, "Delawyering the Corporation"; Barton, "A Glass Half Full."

${ }^{8}$ Corrales Compagnucci, "Tomorrow's Lawyer Today?"; Skjolsvik, "Digitalization of Professional Services."

${ }^{9}$ Schwab, The Fourth Industrial Revolution.

${ }^{10}$ Dubois, "Les algorithmes dans le droit."

${ }^{11}$ Abbott, The System of Professions.

12 Ribstein, "Delawyering the Corporation"; Bigda, "The Legal Profession."

${ }^{13}$ Skjolsvik, "Digitalization of Professional Services."

${ }^{14}$ Jones, "The Use of Technology by Gold Coast Legal Practitioners."

${ }^{15}$ Webley, "The Profession(s)' Engagements with LawTech."

16 Thornton, "Towards the Uberisation of Legal Practice," 46, 50.

${ }^{17}$ The verb "engineer" refers here to the (collective) activities through which some lawyers conceive and create LegalTech projects.

${ }^{18}$ Stanford Law School, "2019 Statistics." Website consulted on March 7, 2020.

${ }^{19}$ Village de la Justice, "Guide and Permanent Observatory of LegalTech and Law Start-ups"; Thomson Reuters, LegalTech Startup Report.

${ }^{20}$ De Jong, "Etat des lieux des LegalTech en France," 31.

${ }^{21}$ Incubateur, "The Legal Startups Incubator."

${ }^{22}$ Rhattat, "L'incubateur du Barreau de Paris," 55.

${ }^{23}$ van Wassenhove, Livre Blanc Guide.

${ }^{24}$ See Avocats.be, "Home"; Legal Tech, "Home."

${ }^{25}$ Dubois, "Entre nécessité et opportunités."

${ }^{26}$ See L'Incubateur, "Incubateur Avocats.be."
} 
the field of law, in the "LegalTech" and "Lawyer" categories. Nominees and winners of the award include the entrepreneurial lawyers who have been engineering and developing LawBox, Online Solution Attorney (OSA), and jm-a.be. ${ }^{27}$ As such, this article focuses on these three LegalTech projects to analyze how and why they have been engineered by some entrepreneurial lawyers. The next section details the selection of these specific cases.

\section{A Project-based Analytical Framework}

The notion of "project" is of primary importance here, and not only because digital technologies provide new opportunities for entrepreneurship ${ }^{28}$ and require new business models. ${ }^{29}$ The combination of a literature review and my empirical study (see the next section) progressively led to identifying four remarkable traits of LegalTech projects.

First, LegalTech projects consist of continuous, relentless, and fast organizing processes that are both open and indeterminate. ${ }^{30}$ Joas $^{31}$ referred to this openness and indeterminacy as "creative action" to refer to the confrontation of both the project and its stakeholders with the unexpected. Second, LegalTech projects are oriented toward the engineering, building, and management of a vibrant digital platform, which becomes the central focus of the innovation. ${ }^{32}$ If projects aim to shape a platform, this platform, in turn, structures the organizational body keeping it alive. Third, while contingent opportunities and multiple microdecisions help to progressively determine ongoing projects, these are often diluted in process-based approaches. ${ }^{33}$ However, a preliminary decision authorizes every project and, in so doing, shapes its contours. As a consequence, any account of projects as creative processes can be completed by another account of projects as institutions, as they have been instituted by a preliminary decision authorizing them. ${ }^{34}$ Fourth, projects are composed of behavioral patterns that are relatively stable and that might be called "strategies." As Crozier explained:

a strategy, therefore, is nothing other than the inferred basis, ex post facto, for the empirically observed regularities of behavior. It follows that such a strategy is in no way synonymous with willed behavior ... any more than it is necessarily conscious. ${ }^{35}$

In the case at hand, these strategies are threefold: organizational, market-oriented, and professional. They are organizational in that the projects involve interdependent actors, whose interactions tend to be formalized, contracted, and sometimes circumvented in the shadow; they are market-oriented, as the projects are inspired by the prospect of selling new online legal services; and they are professional, as the projects are shaped by a dynamic relationship between "control" and "autonomous regulations," 36 dealing, in particular, with legal and ethical frameworks. Far from any temptation toward "psychologism," these strategies depend less on actors' personal objectives than on the characteristics of their-organizational, professional, and market - contexts of action. Within these contexts of action, they discover new means and sometimes redefine their goals accordingly.

As a consequence, LegalTech projects can be defined as open and creative organizing processes aiming to create digital platforms; authorized by a preliminary decision, they are composed of market, professional, and organizational strategies. These four traits inform the project-based analytical framework applied in the following section.

\section{Empirical Description and Methodological Precision}

Fieldwork for this study was conducted in Belgium in 2019 and early 2020. It focused on a selection of three contrasted LegalTech projects that were emerging between 2015 and 2016. These are Lawbox (in 2015), OSA (in 2016), and jm-a.be (also in 2016). This limited corpus shares some important characteristics: each project was developed by one or two lawyers aged between 34 and 45 years old, and is run by small teams of three to six employees. They cover various ranges of services, clients, and legal domains, and all enjoy a certain visibility through media coverage and awards. Finally, each project has been followed by a secondary project in the last two years. These characteristics position these innovative projects as potential new competitors on the Belgian (but also international) legal marketplace. Table 1 describes the three projects according to their size, clients, types of services, awards, and secondary projects.

\footnotetext{
${ }^{27}$ See Lawbox, "Home"; Online Solution Attorney, "Services Juridiques en Ligne"; Jean Marot Lawyers, "JM-A Avocats Huy."

${ }^{28}$ Nambisan, "On Open Innovation, Platforms, and Entrepreneurship."

${ }^{29}$ Lentsiou, "Do the New Business Models Provide 'Justice' to Legal Services?"

${ }^{30}$ Bréchet, "À la recherche de l'entrepreneur"; Latour, Aramis.

${ }^{31}$ Joas, The Creativity of Action.

${ }^{32}$ Yoo, "Organizing for Innovation in the Digitized World."

${ }^{33}$ Giraudeau, "Le travail entrepreneurial."

${ }^{34}$ Giraudeau, "Le seuil de l'action," 42.

${ }^{35}$ Crozier, Actors and Systems, 25.

${ }^{36}$ Reynaud, Les règles du jeu.
} 
Table 1: Brief Description of the Three LegalTech Projects Under Study

\begin{tabular}{|c|c|c|c|c|c|}
\hline & Size & Clients & Services & Awards & Secondary projetcs \\
\hline $\begin{array}{c}\text { Lawbox } \\
\text { (2015) }\end{array}$ & $\begin{array}{l}6 \text { workers } \\
\text { including } 1 \\
\text { founder and } \\
\text { shareholder } \\
\text { - A network of } 11 \\
\text { lawyers/legal } \\
\text { documents writers }\end{array}$ & $\begin{array}{l}\text { - SMEs \& start- } \\
\text { ups } \\
\text { - Legal } \\
\text { departments } \\
\text { - Lawyers and } \\
\text { law firms } \\
=\text { firms }\end{array}$ & $\begin{array}{l}\text { Automated creation of legal documents (general } \\
\text { terms and conditions of sale, commercial leases, } \\
\text { business and employment contracts, etc.) that are } \\
\text { sold either on a single purchase basis, or as } \\
\text { document packs (https://www.lawbox.be), or as a } \\
\text { document assembly software for legal professionals } \\
\text { (https://lawboxpro.com) }\end{array}$ & $\begin{array}{l}2019 \text { award for the most } \\
\text { innovative legal tech company - } \\
\text { LegalTech summit, organised by } \\
\text { the Belgian bar associations }\end{array}$ & $\begin{array}{l}\text { Diversification: partnerships } \\
\text { (https://www.pactecoloc.be) } \\
\text { and white labeling } \\
\text { (https://legalsmart.partena- } \\
\text { professional.be/meer/lawbox- } \\
\text { verhaal; } \\
\text { https://www.smartlegaldoc.eu) }\end{array}$ \\
\hline $\begin{array}{c}\text { OSA } \\
(2016)\end{array}$ & $\begin{array}{l}\text { - } 2 \text { founders and } \\
\text { shareholders + } 1 \\
\text { IT developer } \\
\text { - A network of +/- } \\
150 \text { lawyers }\end{array}$ & $\begin{array}{l}\text { - Lawyers } \\
\text { - Private and } \\
\text { economic } \\
\text { individuals }\end{array}$ & $\begin{array}{l}\text { Linking lawyers and clients / online legal } \\
\text { consultation } \\
\rightarrow \text { Referencing \& visibility }\end{array}$ & $\begin{array}{l}2019 \text { finalist for the most } \\
\text { innovative legal tech company - } \\
\text { LegalTech summit, organised by } \\
\text { the Belgian bar associations } \\
2018 \text { Finalist - Trends Legal } \\
\text { Awards }\end{array}$ & $\begin{array}{l}\text { Legal design } \\
\text { (http://www.lawgitech.eu/lawgi } \\
\text { techfr/lawgitechdesign.html) }\end{array}$ \\
\hline $\begin{array}{c}\text { J-ma.be } \\
(2016)\end{array}$ & $\begin{array}{l}\mathbf{1} \text { founder and } \\
\text { shareholder +1 } \\
\text { IT developer }\end{array}$ & $\begin{array}{l}\text { Real and } \\
\text { potential } \\
\text { individual } \\
\text { clients }\end{array}$ & $\begin{array}{l}\text { Tools (online breathalyzer, speed/alcohol roadside } \\
\text { fine calculator, air/blood alcohol impregnation } \\
\text { conversion) } \\
\text { - Information (liabilities, insurance, medical } \\
\text { expenses, incapacity for work, medical advice, } \\
\text { expertise, compensation, legal advice, etc.). } \\
\rightarrow \text { Referencing \& traffic }\end{array}$ & $\begin{array}{l}2018 \text { public crush at the price of } \\
\text { the most innovative LegalTech } \\
\text { company - LegalTech summit, } \\
\text { organised by the Belgian Bar } \\
\text { associations } \\
2016 \text { innovation award of the } \\
\text { Liège Bar Association }\end{array}$ & $\begin{array}{l}\text { https://www.LegalStreet.be } \\
\text { Digital platform for road and } \\
\text { medical accident victims }\end{array}$ \\
\hline
\end{tabular}

OSA: Online Solution Attorney

The three projects provide a small-scale and empirical understanding of the heterogeneity that characterizes LegalTech projects. Their entrepreneurs are passionate about information technology, and all specialized in various fields. A1 is the founder of Lawbox, is in his forties, and specialized in commercial law, intellectual property, and laws surrounding new technologies. B1 and B2 are two lawyers who founded OSA. Both are in their thirties and specialized in commercial and corporate law, contract and distribution law, e-commerce, liability, and insurance law. As for C1, this 30-year-old lawyer and founder of jm-a.be specialized in liability and insurance law as well as the assessment of personal injury.

These four lawyers have engineered contrasting projects: Lawbox is a tool for the automated creation of legal documents; OSA is a matchmaking platform for bringing lawyers and clients together, and for providing online consultation; and jm-a.be is a website that provides clear information and playful tools, such as an online Breathalyzer, a road-fine calculator, and an air and blood alcohol impregnation converter. These projects all target various categories of clients, including companies and entrepreneurs for Lawbox, lawyers and prospects for OSA, and prospects for jm-a.be. They also gave rise to different organizational structures and business models.

Lawbox consists of six employees, including the founder's "right-hand man" (who is also a lawyer), an IT manager, a project manager, and four platform developers. The organization is located in Brussels, Belgium, and relies on a network of 11 lawyers who have authored various legal documents including (but not limited to) general terms and conditions of sale, commercial leases, business contracts, partnership agreements, management contracts, documents for the protection of intellectual property, general terms and conditions of use of a website, and employment contracts. These documents can be sold either directly to start-ups or through an online shop to small and medium-sized enterprises (SMEs). The documents are on sale from EUR€49, and document packs are available from EUR€199. ${ }^{37}$ Larger companies can also purchase a professional license (i.e., document assembly software for corporate counsels and law firms). ${ }^{38}$ In the last two years, Lawbox has been diversifying its activities through two types of projects. The first offers specific services to a privileged partner's customers, such as access to collocation agreements offered by AXA to its insured individuals. ${ }^{39}$ The second provides large groups such as AXA or Partena ${ }^{40}$ (a social secretariat) with so-called "white-labeled platforms," which allow their clients to draft documents for their daily life needs.

OSA was founded by a couple of Brussels lawyers who rely on an IT developer and a network of nearly 110 lawyers registered on the platform. Every registered lawyer has an online profile on which he or she can enter his or her contact details and, thus, be reached directly by clients. Clients can also use the platform to make an appointment at a lawyer's office, consult a lawyer online through Skype, or ask a question by e-mail. For each of these modalities, the lawyer can indicate a fee rate, which varies according to the modalities and the expectations and/or reputation of the lawyers. Thus, OSA enables lawyers to not only build

\footnotetext{
${ }^{37}$ Lawbox, "Prices."

${ }^{38}$ See LawboxPRO, "Home."

${ }^{39}$ See Lawbox Colocation, "Home."

${ }^{40}$ See AXA, "AXA: Główna"; Partena Professional, "Home."
} 
an online presence and increase their visibility if they do not have a website, but also secure improved referencing of their site if they already do. In addition to OSA, B1 and B2 have gradually expanded their activities toward legal design. ${ }^{41}$ This methodology aims to express legal frameworks using clear and accessible language. It is thanks to the interweaving of technological (e.g., graphic design, decision trees, etc.) and legal (IT law) skills that they have been able to enrich their activities.

Finally, jm-a.be is the website of a legal office based in Huy, Belgium, close to Liège, bringing together four associate lawyers (including the founder) and an in-house IT developer. In two years, the website has generated a significant number of visitors, some of whom (even if they are rare) contact the firm and sometimes submit a file. Some pages on the site receive more than 10,000 visits each month thanks to entertaining and informative content. Thus, jm-a.be contributes to improving clients' website referencing as well as the image and reputation of law firms. In 2018, C1 and his IT developer were developing a second platform, known as Legal Street, ${ }^{42}$ which calculates the amount of personal injury compensation for road and medical accident victims. They received the innovation prize from Avocats.be in 2018.

In addition to gray and scientific literature reviews on LegalTech services and start-ups, every project has been analyzed using a triple methodology. First, web searches were conducted to collect some "manifestos" (i.e., "introductory statements outlining the goals and processes of each site"). ${ }^{43}$ Manifestos include online publications relating to "who" a company is, "discovering" their solutions, "reading" more about their experience, blogs, interviews in the press, and posts on LinkedIn. Second, 11 semidirective interviews were conducted with three founders and two IT developers $(n=5)$, focusing on the genesis of their projects, rationalities, organizational and market-oriented strategies (business plans and business models), networks, relations to the Bar Association and other professional/institutional bodies, and the problems they encountered. Additional semi-directive interviews were conducted with two clients of these start-ups $(n=2)$, two representatives of the Bar Associations $(n=2)$, and two members of the Belgian LegalTech network, notably LT Connect $(n=2)$. Every interview was conducted in French and subsequently translated to English for the purpose of this article, and lasted between one hour and two-and-a-half hours. All discussions provided both a rational perception and a meaningful interpretation of participants' working experience and environment. Finally, field notes were taken during professional conferences and congresses, training, and in information sessions. ${ }^{44}$ This qualitative-and, therefore, nonrepresentative-material has been examined through textual analysis, using open coding techniques to identify persistent themes.

\section{Four Remarkable Traits of Three LegalTech Projects}

This section applies the project-based analytical framework presented earlier in the paper. It draws on four remarkable traits of the projects under study and aims to account for the preliminary decisions, the platform, the turning points, and the strategies composing them. ${ }^{45}$

\section{Opportunities of Preliminary Decisions}

A1 (Lawbox), B1 and B2 (OSA), and C1 (jm-a.be) are four lawyers who were detecting, over the course of 2015, certain needs that were specific to them. For example, A1-whose activity consisted of drafting legal documents for SMEs, self-employed people, and starters - was systematically adapting preexisting templates to unique requests. This standardized method of work and clients' narrow budgets were limiting his services' added value and price. Therefore, he wished to automate his working process to produce more requests faster and, thus, generate a higher profit margin. In OSA's case, B1 and B2 are two lawyers. B1 was pregnant at the time and, for medical reasons, could not travel by plane and continue representing clients in Asia as she used to do for a big law firm based in Brussels. She suddenly had to find new clients on the Brussels market and, together with B2, wished to engineer a platform for connecting lawyers and (potential) clients. Finally, C1 wanted to develop a website that informs visitors and, above all, activates his clients (in particular) by allowing them to consult their files online.

Each lawyer then progressively refined the definition of their specific needs by questioning the practices of both clients and competitors on the legal (and nonlegal) marketplace, and by drawing inspiration from some famous US-based initiatives:

In observing the market, I have seen two things. Some clients were copying and pasting templates that were available online for free, but they were not well protected. Other clients had more money and went to a reputable law firm. They were receiving

\footnotetext{
${ }^{41}$ Lawgitech, "Lawgitech Design."

42 See Legal Street, "Home."

${ }^{43}$ Carlson, "News Startups as Agents of Innovation," 567.

${ }^{44}$ See Legal Tech, "Home"; Reshape Legal, "Legal and Tech Summit"; van Wassenhove, "Free Digital Training in Bars!"

${ }^{45}$ Among these four traits, the first and third ones have been inverted here for chronological reasons, as opportunities and authorizations come first, followed by a platform that is constantly being organized by creative rationalities and composed of various strategies.
} 
ill-adapted but very expensive documents, because big firms apply hourly rates ... Then, by chance, I came across Rocket Lawyer, a platform created by an American lawyer facing the same problem as mine. I was clearly inspired by it. (A1)

On the one hand, we felt the need, among young lawyers like us, to consult online ... And on the other hand, we thought about the clients' experience - how to choose a lawyer, how to get in touch with him/her, how to set a fee, give a deadline. Our primary concern is that the process must be good for the client. As for the lawyer, he or she is free to set the fees on a fixed or hourly basis, to consult online or offline, etc. We also looked at foreign experiences, especially those conducted by the National Council of French Bars and Avvo.com. (B1 and B2)

$\mathrm{C} 1$, for his part, was observing that many lawyers' websites were only displaying their contact details and were conceived as "simple online showcases." He also noticed that, for 20 years, several companies were activating their clients, such as banks delivering them various information through a personal account, without the intervention of a professional.

Although all four parties were specifying their projects by putting their needs into perspective within the market context, they were also identifying the respective contours while mobilizing their technical skills to develop specific internal tools. They subsequently faced a second-general rather than specific — need to internalize some necessary technical skills:

\begin{abstract}
We drew our plans, we knew how to tinker with computers, but very quickly, we turned to Claude, a web designer. He made us a great site, allowing consultations by Skype and e-mail. We founded a limited liability company and OSA really started. (B1 and B2)
\end{abstract}

\begin{abstract}
I started developing my site alone. But I needed software and my cousin, Raphaël, is a reference in the field. He was selfemployed at the time. He helped me to do something very good ... In 2015, I asked him to help me develop online services on my site. I felt something was possible and he joined the firm in 2017. He developed four tools that are still at the roots of the page structure: consult your lawyer online; consult your file online; send files to the law firm; make appointments. It worked right away. (C1)
\end{abstract}

All these developments have been processing progressively, enabling the entrepreneurs to detect their specific needs, to progressively define the contours of their project by observing production and consumption practices on various marketplaces, and then develop an internal tool for different purposes, including automation, networking, information, and online consultation. Over time, these projects have also been involving IT developers, taking various contractual forms such as partnerships, association, or employment. These developments have been taking place in a highly institutionalized context. Indeed, the four entrepreneurs are lawyers and, as such, are subject to the authority of the Bar Association and to the respect of legal and deontological frameworks. Such frameworks are characterized by the presence of both resources and constraints:

Much reliance has been placed on the unprecedented context in which advertising, display of prices, and online consultations are now allowed ... All this, obviously, in compliance with the rules of deontology, authorized us to define a very tight project. For example, we make sure that clients have three boxes to tick for an order, because a European jurisprudence defines this condition. (C1)

While developing the platform, we wrote to the Brussels Bar to warn them. No news for six months ... But when we informed about our project on LinkedIn, we have immediately been summoned to the President of the Bar Association ... We've been asked questions about confidentiality guarantees, data anonymization, etc. As a result, the President was convinced that the platform was a good initiative. His only demand was to make it explicit that the platform was not an initiative of a law firm. That suited us, so there is no conflict of interest! (B1 and B2)

This extract reflects the influence of a specific professional norm, such as the one that also led A1 and C1 to inform the Bar Association:

I immediately went to present the platform to the Council of the Bar Association. I felt comfortable going there, as I had three, four friends there. The President of the Bar was very happy to see that the platform was engineered by a lawyer. He was also enthusiastic about our role of "online legal editor." He found this was very important because more and more lawyers are writing contracts and putting them online. But at Lawbox, it's different because we are not simply publishers, but [also] editors. (A1)

We can now understand how a preexisting institutional space composed of bodies (Bars, Order), rules (deontology), and normative frameworks (bottom-up information, top-down authorization) has been authorizing the three LegalTech projects in question. It should also be mentioned that each project relies on the existence of a specific law firm, ${ }^{46}$ with each allowing the project to start up without being immediately profitable. Other LegalTech projects, led by nonlawyer entrepreneurs, probably

\footnotetext{
${ }^{46} \mathrm{~A} 1$ is an associate lawyer of Lex4u; B1 and B2 are associate lawyers of Lawgitech; C1 is an associate lawyer of Jean Marot Lawyers.
} 
need to raise funds more quickly. ${ }^{47}$ The processes of engineering and developing a LegalTech project are, thus, based on both situated opportunities and preliminary decision rather than on an intrinsic/absolute necessity, ${ }^{48}$ contrary to what is suggested by the abovementioned literature (see the first section). In light of these elements, we should also consider that the three LegalTech projects under study have been emerging in entrepreneurial agencies rather than originating from entrepreneurial lawyers' own ideas.

\section{Organizing an Organizing Platform}

Following Yoo, ${ }^{49}$ digital projects consist of continuous, relentless, and fast organizing processes aiming to engineer, build, and maintain a vibrant platform, which is the central focus of the innovation. While being shaped by organizing processes, LegalTech platforms are also structuring said organizations and keeping them alive.

At the center of the three projects lies a digital platform, ${ }^{50}$ which is the visible and dynamic result of an innovation project. Each platform has been collectively engineered and developed by a network of individuals and tools. Indeed, some strong and local social ties weave each entrepreneurial network. For example, A1 was first assisted by some of his IT and starter customers to automate his work processes and to engineer the Lawbox platform. This platform is now mobilizing 11 specialized lawyers who are in charge of drafting legal documents, as indicated on the Lawbox website:

\section{Our authors are passionate about law and have a solid experience in contract law. The contracts you have at your disposal have been drafted according to their preferred subjects. Many of them also write articles in law journals or pass on their knowledge by teaching at university. As good professionals, our authors make a point of constantly updating their knowledge. They do this in particular by attending training courses. This enables them to guarantee you legally up-to-date contracts. ${ }^{51}$}

$\mathrm{C} 1$, for his part, employed his cousin, a computer scientist, for development of his website. As for B1 and B2, they first set up a limited liability company with their IT developer to create and maintain the OSA platform. Then, they mobilized some close colleagues, through social networks, as early adopters. Today, the platform allows clients to contact one of 116 registered lawyers.

Conversely, entrepreneurial networks are built around online, globally available software. These tools constitute the material dimension of every LegalTech platform. As B2 explained, "we use a lot of tools like [Adobe] Photoshop, HTML, social media, graphics software, [remote server administration] tools, database software, customer relationship management tools, etc."

Each platform articulates humans and technologies. ${ }^{52}$ This sociomaterial assemblage structures an organizational body, as reflected by each website categorizing the project stakeholders. Thus, the Lawbox website distinguishes the four members composing its team from the lawyers listed as authors; the jm-a.be website also distinguishes the four lawyers composing the small-sized law firm from the IT developer in charge of LegalTech. As for OSA, it highlights the lawyers listed in its directory but remains relatively discreet about the organization managing and maintaining the platform. This is explained by the fact that the potential ordering process is completely automated, but also avoids controversy: that is, until a few years ago, lawyers could not manage any other company than their own firm. This is why B1 is the manager: she ensures both the legal follow-up and compliance in different countries, but does not consult on the platform to avoid any doubt in terms of conflictual interests. B2 takes care of social networks, conferences, and presentations (sometimes with B1).

The structuring effect of a platform on the organizational body keeping it alive is materialized by identification of a collective (i.e., a team or a network) of a formal division of labor (vertical division between team and authors at Lawbox; vertical division between specialized lawyers at OSA) and various coordination mechanisms. These are essentially standardized work processes, such as the sections "how to create your lawyer account" and "how do I place an order?"53 on the OSA platform.

Another structuring effect of the platforms on work organization lies in the flexibility of staff. For example, $\mathrm{C} 1$ and his cousin had to learn how to work with "permanent and time-consuming" notifications from the chat room. Like A1, they are also gradually moving their firm toward a paperless organization, as more clients require online consultation. The four

\footnotetext{
${ }^{47}$ This assumption indicates one of the methodological limitations of this article as well as a direction for further research.

${ }^{48}$ Kuty, De la valeur à la norme.

49 Yoo, "Organizing for Innovation in the Digitized World."

${ }^{50}$ Or two platforms, in C1's case, jm-a.be and Legal Street.

${ }^{51}$ Lawbox, "Authors."

52 Orlikowski, "Sociomaterial Practices."

${ }^{53}$ Online Solution Attorney, "Create Your Lawyer Account"; Online Solution Attorney, "How it Works."
} 
entrepreneurial lawyers also indicated that maintenance of their platform is a permanent and full-time job, particularly in adapting technological devices to regulatory constraints:

The management and maintenance of a platform like this one is a continuous learning process: IT solutions are constantly evolving; you always have to configure, reconfigure, invest, reinvest, respond to new problems, modernize and simplify the tool, adapt to mobile [technology], etc. But the legal framework is also constantly evolving. For example, we make sure that customers have three boxes to click before placing an order, because European case law defines this condition. (B1)

We still have to make small adjustments to be even clearer with regard to the [General Data Protection Regulation], and we adapt our chat software accordingly. We are also building on the customer experience, using mobile-first technology. (C1)

These elements indicate how material (technological and legal) and social components of digital platforms intertwine. ${ }^{54}$ They also shed light, once again, on the interdependency between the technological and legal constraints (and resources) populating the institutional context in which LegalTech projects are evolving. Therefore, it is appropriate to conceive of them as both temporarily organized forms and open—although technologically and legally framed—organizational processes.

\title{
Openness and Creative Rationality
}

Beside their structuring effect on organizations, LegalTech projects are also open and indeterminate organizing processes. Their development has, in each case, taken an unexpected turn and scale. First, unexpectedness characterizes the genesis of the projects, as illustrated by the case of OSA, imagined at a time when B1 was in a position to seek out new customers in a local market. A similar opportunity also led $\mathrm{C} 1$ to recruit a cousin, an IT developer looking for a stable working environment. Another component of indeterminacy lies in the unexpected meetings informing a project:

\begin{abstract}
This is how the transition to the professional license happened. Mr. X, a client, wanted to benefit from my services as a lawyer to set up his investment fund in the Grand Duchy of Luxembourg. His needs quickly exceeded my skills. I referred him to a specialized firm, but he wanted me to help him with all the compliance documents. I then gave him access to the platform so that he could generate his own documents, which I then adapted. He paid me one hour for the adaptations. He enjoyed the platform experience: he used it at home, in the evening, and had access to all sorts of standard documents. He was the one who saw that a platform accessible to customers was a source of mutual added value-for them and for me. He tried to convince me to put the platform online. I had some doubts. Then I observed that, for social matters, social secretariats do that. But for start-ups and small traders, nothing exists. We discussed it and I put the platform online with an all-in password. Immediately, I started selling about two documents a week without doing anything! I was timid and I was afraid of failure, but Mr. X pushed me to think bigger. (A1)
\end{abstract}

If the meeting with Mr. X allowed A1 to glimpse new perspectives for the development of their project by creating a "pro license" - in addition to the single purchase of documents - other events can also influence the development of a project. This is notably the case for OSA, which, on the opinion of the President of the Antwerp Bar Association, forced the company to modify its business model and further abandon certain ideals that were at the origin of the project. As B2 explained:

OSA connects clients and lawyers. Originally, we were charging the lawyer for the platform fees. The idea was to split the costs between the lawyers and allow them to deduct them for tax purposes. That was making sense because the platform was doing a lot of automation work that benefited the lawyer without affecting the cost price. But one day the President of the Bar of Antwerp issued an opinion according to which we were importing business. We then had to change the general conditions of the site and we are now charging the clients for the platform fees. Nobody wanted to hear our arguments. Many platforms do not display lawyers' direct contact details: their telephone number is often replaced by a toll-free number. De-referral is an ethical offense, but hiding service providers to enhance intermediation is a trendy business model.

If reframing processes are inherent to a project, it is because each one is a process of collective and dynamic action. Each one is gradually developed not only in response to a professional context, as in the case of OSA, but also to the market, as in the case of Lawbox (Mr. X, a client, opens up new perspectives to the project) and jm-a.be. For example, C1's project first concerned his firm's website and then the development of the Legal Street platform:

Legal Street has been emerging gradually in our minds through discussions with Raph [C1's cousin]. We were challenged by the technological resources, especially [optical character recognition] recognition and "mobile-first" applications. We had the online record of traffic offenders, and we thought we could develop it for victim records as well. This is how we imagined that victim clients would be able to track and manage their file online thanks to an [optical character recognition] module, rather than coming here with their file in hand. Specifically, throughout the case, the victim has to consult doctors. For each visit, (s)he is entitled to ... medical and travel expenses. Thanks to the application, the victim is geolocalized and the module

\footnotetext{
${ }^{54}$ Orlikowski, "Sociomaterial Practices."
} 
automatically calculates the home-doctor distance, then converts the kilometers into euros. Everything becomes so intuitive with an app. It reduces delays and costs, also administrative work, stress, and travels. (C1)

Development of the project carried out by B1 and B2 also went through the mourning process of certain ideas and some rebounding to new perspectives. Following reframing, and in the absence of a blanc-seing from the Bar Association, they gradually realized that their technical skills allowed them to provide integrated solutions to their clients with very little subcontracting. This is how they have been specializing in legal design:

\begin{abstract}
It's not much more expensive than our ordinary work but it's more profitable than associating a lawyer with a developer or a graphic designer. For example, we do the legal design ourselves, using Photoshop, Wacom, etc. When I work on [General Data Protection Regulation] data processing, I can access the servers, administer them, check them, and test the client's cybersecurity. I can also use my technical and legal skills to make the privacy pop-ups that we implement on our clients' sites (WordPress, HTML, etc.), but I can also help the clients with their e-reputation. The tricky exercise is not to become a competitor of some clients by focusing on the meeting point between law and tech. (B2)
\end{abstract}

Reframing, renunciation, and rebounds compose the open processes of the three projects under study. Each platform participates in these open processes through iteration, as the launch of a platform is followed by progressive reviews and evaluations that define a practical development method. The concept of absolute rationality, therefore, fails to account for the processes of emergence, conception, and development of the projects. Indeed, over time, the actors involved in each project pursue a quest for opportunities and a means of action just as much - if not more- than for ends and objectives. As such, the projects are instead processes taking place over longer or shorter periods of time (four years for each main project studied) and are punctuated by concrete achievements, such as the development of an internal tool, the marketing of documents on a singlepurchase basis, and then a "pro license" at Lawbox. The development of OSA sees the addition of successive modules (consultation by e-mail, online payment, online consultation by Skype, online consultation by phone, and appointment made at the office, etc.), followed by redefinition of the business model, among other processes. Finally, development of the jm-a.be website sees the successive addition of various tools, and then development of the Legal Street platform. If concrete results are valued, this is also the case for problems and renunciations, which are considered by entrepreneurs as sources of learning. Evidently, the concept of bounded rationality ${ }^{55}$ helps in accounting for project processes that have less straightforward trajectories. ${ }^{56}$ Confrontation with the unexpected makes it possible to perceive certain objectives as inaccessible or too unambitious, and unsuspected or incompatible with market and professional norms. Therefore, it is a reactive and projective rationality that best helps to account for the collective capacities, more or less opportunistic and visionary, making it possible to initiate and redefine a mobilizing project. This refers to the concept of creative rationality, ${ }^{57}$ which cannot be totally reduced to the concept of bounded rationality.

\title{
Organizational, Market, and Professional Strategies
}

\section{Organizational Strategies: Experimental and Incremental Innovation}

The development of a LegalTech project takes place in a sociotechnical network, within which an organization is (being) structured around a platform. In the case of Lawbox, this organizational development was not planned but shaped by the bounded and creative rationality of its stakeholders:

I didn't immediately have the mentality to develop a business plan, raise funds, define the product, take care of branding, marketing, sales, etc. ... After a year, I needed funds to hire a collaborator. Mr. X put me in touch with an IT company. They were interested in the project but couldn't invest any money. So, they provided me with a full-time developer for six months. In short, they invested for a third of my company ... And now, we have to raise funds to hire sales managers. We have to grow. (A1)

The development of each project has entailed risks, particularly financial ones as well as (to a lesser extent) reputational ones, for each law firm:

Having an in-house IT developer was atypical at the time because we had a very small structure: there was me, a collaborator, and my secretary! It was a risky business. But the risk is calculated in our sector because accident victims are almost always insured for legal protection. So, we almost always have a third-party payer. In short, it's the insurer who pays; we and the victims don't bother. That's why I don't need any financial plan or business model. (C1)

\footnotetext{
${ }^{55}$ Simon, "Bounded Rationality in Social Science."

${ }^{56}$ Kuty, De la valeur à la norme.

${ }^{57}$ Joas, The Creativity of Action.
} 
Although the financial risks incurred by $\mathrm{C} 1$ appear to be limited by the presence of third-party payers in his market segment (i.e., insurance law), these risks were the subject of a specific calculation in the case of OSA:

We work with an engineer who calculates the fees so that they decrease as the lawyers' consultations via OSA increase. He has developed a collaborative algorithm. Recently, this model has been adapted with the move to end-customer billing to apply a limited fee of up to EUR€25. When we switched to invoicing to the end customer, the collaborative aspect was somewhat forgotten. (B2)

It appears here that the engineering and development of a LegalTech project by lawyers is not part of a predefined plan. The lawyers studied here have become entrepreneurs gradually, over the course of meetings and experiences, in a rather empirical way, at the price of more or less calculated risks. They all share incremental and experimental logics of innovation, which shed light on the contingent nature of their projects.

\section{Market Strategies: Expansion, Referencing, and White Labeling}

The engineering and development of a LegalTech project aim to provide online legal services. The three projects under study demonstrate three market strategies. The first aims to expand the geographical territory in which the platform's legal services are offered. Thus, Lawbox and OSA have been undertaking international development of their services, and C1 has been developing Legal Street to increase the volume of activities carried out online and to amortize the IT investments of his law firm:

The advantage of technology is that you are not bound to a territory. We are also active in France, Spain, [the] US, Poland. Abroad, we look among local colleagues, we see modern law firms, we are always warmly welcomed because all lawyers are looking forward to increasing their visibility. (A1)

We are now operating abroad, in France, Luxembourg, and Spain. (B2)

With Legal Street, we wanted to go further than the initial approach of [the] jm-a.be website, to go beyond the image of the Huy-based firm. For some, Huy is too small. And then others think that a lawyer is expensive, whereas a platform is a matter of services at an affordable price, a bit like Amazon. (C1)

Referencing is a second strategy. It aims to increase the visibility of the platform, the number of visitors and, consequently, the number of customers. To this end, platforms combine paid referencing (e.g., Google AdWords) and natural referencing. The latter consists of offering informational content on blogs, threads, and news alerts relating to various themes, using questions and keywords. Awards, press articles, and LinkedIn publications also contribute to platform visibility. As C1 explained:

we are looking for customers rather than for visitors! But visitors already have one foot in the office. To get their second foot in, we use the form where they can enter their contact details, and we have the chat ... Sometimes, the website is consulted for information and it allows us to create a contact, and this contact can lead to a file. That's where the real added value lies. Recently, a Romanian truck driver was blocked in Arlon for a traffic offense. His employer Googled a lawyer and e-mailed us.

Another strategy aiming to increase the visibility of a platform consists of providing some big companies with a white-labeled application. These companies can then create their own branded product lines and offer innovative services to their clients, for free or at a reasonable price. As big companies are important due to their size and reputation, a white-labeling strategy allows Lawbox, for example, to display the names of some prestigious clients and partners (such as AXA and Partena) on its website and, as a result, increase its reputation and online visibility:

In the last six months, the profile of our clients has been evolving. First, they were SMEs and starters. It was great, but they offer a rather small profit margin. Recently, we have been approached by big companies such as AXA and Partena that are in touch with our target audience. At AXA, Mr. $Z$ wanted to offer an innovative, free service to his clients. Our partnership means that we make the platform available to these big companies. In turn, they make us shine and open up new perspectives. That's how we recently came to work for Carrefour. (A1)

There is nothing surprising that a platform selling legal documents and producing faster and cheaper services aims to increase its profit margin. However, neither the commercialization of their services nor the quest for profit was the primary objective of OSA and jm-a.be. Rather, it was the search for reputation, innovation —intrapreneurship — and diversification of their activities:

Our primary objective is to help the profession. Because we're both self-employed, we see that it is not always easy to get through the month ends. And many young lawyers starting out in the profession are in big financial troubles. OSA simply aims to help them. (B2) 
The tools we have been developing are free services. Some tools are little consulted, others more. But none of them have been developed with the aim to make money ... In the beginning, I just wanted to shape the image of the dynamic and connected, young, modern lawyer. Of course, the objective is also to capture some clients, but this is a secondary goal. (C1)

Even in the case of commercial services like those provided by B1 and B2 in the field of legal design, "the tricky exercise is not to become a competitor of some of our clients" (B2). Commercialization, in this case, consists of a prudential practice. ${ }^{58}$

We now see more precisely how entrepreneurial lawyers adopt some market strategies such as internationalization and deterritorialization, referencing and white labeling. This illustrates how economic activities such as online legal services are socially embedded in local orders, ${ }^{59}$ as well as in institutional professional orders, as shown in the following section.

\section{Professional Strategies: Authorizing and Knowledge Hybridization}

This paper has already shed light on the central role played by the Bar Association and, more generally, by the profession that authorizes or sanctions LegalTech projects, sometimes crowns them with awards (as in the case of Lawbox and jm-a.be), or reminds them of some legal and/or deontological principles (as in the case of OSA and its pricing scheme). The analysis also highlights the importance of professional networks in terms of project dissemination and collaboration, as such networks can provide them with a legal document's author(s) (Lawbox) and platform user(s) (OSA). Professional stakes and assets appear, here too, as being socially embedded in local orders, where previous connexions matter as much as reciprocal interests.

The analysis has also shown how entrepreneurial lawyers influence their profession. First, they contribute to strengthening the entrepreneurial role recently endorsed by the Bar Association, as they incarnate the "technological innovation wave" mentioned by President of the Belgian French-speaking Bar:

We want to support lawyers in the digital transition. This is why we have set up the incubator and why we organize annual conferences on this topic. By highlighting LegalTech start-ups, we encourage lawyers to understand the innovations, sometimes even to undertake them themselves. (Interview, November 22, 2018)

The entrepreneurial lawyers studied here also populate the audience of professional awards and prizes granted by the Bar Association and other law societies, while weaving a Belgian network of LegalTech entrepreneurs (e.g., like LT Connect). As a consequence, they contribute to reinforcing the authority of the Bar Association while legitimizing its entrepreneurial stance and recognizing its key role at the preliminary stage of their projects. Further, our analysis reveals the ethical purpose of some projects on lawyers' profession. As previously noted, the OSA project has been developed with a certain philosophy regarding platform fees and lawyers' referencing. Their project aims, for B1 and B2, to "bring ethics back into the profession" and to promote what they call the "legitimate trust" of their clients:

In fact, there [are] many platforms practicing de-referral ... This kind of attitude is obviously problematic in terms of competition, but it is a choice for legal entrepreneurs: how can legal services be valued if the law is not respected from the outset? Let us not forget that we all take an oath! (B1)

Second, they contribute to a form of hybridization of their professional knowledge, practice, and boundaries. ${ }^{60}$ We previously saw how A1 progressively became both a manager and an entrepreneur to define the product of Lawbox and its market, to draw up a business plan, to adopt branding and marketing strategies, and to gain audacity. In addition to such business and managerial practices and knowledge that B2 and C1 have also been developing, entrepreneurial lawyers are also constantly working with IT tools and knowledge. A1 and C1 follow the IT development of their platform closely, even if they rely on specialized developers. Conversely, C1 observed that his IT developer has acquired remarkable legal skills. As he explained, "our main strength in online consultations is that, after two or three years of experience, Raph knows the subject matter better than many lawyers. And when he can't answer, I take over" (C1).

As for the technical expertise acquired by B1 and B2, it has gradually led them to offer legal-technical or technico-legal solutions, which they described as an "advanced" form of legal design:

The law is not a problem for us. From a technological point of view, I can administer servers, upload pages, [and] code the site. B1 can take care of the coding, the drawings, [and] the design. She's supposed to train me in design. We'd also need a third

\footnotetext{
${ }^{58}$ Dubois, "Prison Governors as Policymakers."

${ }^{59}$ Friedberg, Local Orders.

${ }^{60}$ Abbott, The System of Professions.
} 
hybrid being, but that's like looking for a five-legged sheep. I'm just realizing how much the business is changing and how much the services we offer are changing too. (B2)

This project-based approach then makes it possible to apprehend the reciprocal enactment of entrepreneurial lawyers and their - professional, in particular, but also organizational and market - environment. By embodying, enacting, and inscribing hybrid (legal, IT, and business) knowledge ${ }^{61}$ in their projects, platforms, organizations, and services, they indicate that the professional system to which they belong has porous and shifting boundaries. ${ }^{62}$ This porosity and these shifts allow the legal profession to adapt (even if still marginally) to the changes occurring in the linked ecologies where it evolves.

\section{Conclusion}

This paper accounts for the genetic and organizing processes of three LegalTech projects. This perspective provides both a grounded study and an analytical framework adapted to the legal technology phenomenon. The results of this study reveal that the three selected projects do not break with a previous situation, but rather build on the existing activities carried out by the lawyers initiating them, as well as their partners'. They further highlight that the projects are not driven by individual rationalities but rather by collective, bounded and distributed rationalities, as well as a tendency not to answer to a decontextualized necessity and instead build on contextual and local opportunities. This analysis also sheds light on the mutual influences between entrepreneurial lawyers and their profession. Conversely, LegalTech projects inspire lawyers' professional knowledge and (increasingly automated) practices, while requiring new technological skills from them and making (online) legal information more easily accessible (faster, cheaper, and clearer) to their clients. Equally, professional associations consider these projects as a resource enabling them to inform and sensitize their members to the opportunities offered by new technologies. Indeed, these bodies do not hesitate to reframe some projects in the name of the deontology, of which they are the guardians.

Thus, the three LegalTech projects studied here all organize around specific platforms, each being a catalyst for the project, a sociotechnical object emerging in a normative professional system, and a facilitator between supply and demand. From a market perspective, it appears that these projects increase the competitiveness between lawyers through many tools such as referencing, price transparency, customer capture, and white labeling, among others. Websites, social networks, and networking platforms also increase the chances for lawyers to increase their visibility and, therefore, attract or retain clients. However, this increased competition is framed by both legal and deontological rules. If courts and tribunals have intervened to liberalize communication in the liberal professions, ${ }^{63}$ the lawyer Code of Ethics has also been adapted in the same direction, authorizing lawyers (under certain conditions) ${ }^{64}$ to advertise, deliver online services, and adopt referencing practices. The three projects in this study are coping with these new regulatory opportunities.

Here is where the sociotechnical embeddedness of an increasingly competitive market for legal services becomes apparent. In less than 30 years, this market has constantly shifted from a "professional" configuration, marked in particular by the prohibition of personal advertising and the posting of tariffs, to a resolutely "liberal" configuration, marked by the posting of various tariff formulas, the adoption of referencing strategies, the emergence of rating systems, and the internationalization of legal services. The origin of such a shift clearly appears to be linked not only to institutional factors (e.g., rule of law, professional deontology and regulation, etc.), but above all to the existence of a sociotechnical infrastructure that makes it possible to gather information of various kinds (commercial, professional, technological, legal, etc.) and to move it to consumers and competitors alike. This digital infrastructure contributes to a reciprocal and finer adjustment of supply and demand. Such conditions help to "liberate" both the lawyers studied here and their clients: the former are no longer forced to passively wait for a visit from either wellinformed clients who are guided by their reputation, or from a clientele condemned to random choice. ${ }^{65}$ Yet, does this situation automatically improve the quality of legal services?

\footnotetext{
${ }^{61}$ Freeman, Knowledge in Policy.

62 Abbott, The System of Professions.

${ }^{63}$ In the European context, see the Court of Justice of the European Union, "CURIA," April 5, 2011, aff. C-119/09; in the Belgian context, see Constitutional Court of Belgium, "Grondwettelijk Hof," April 6, 2011, no 55/2011.

${ }^{64}$ In the European context, see Council of Bars and Law Societies of Europe, CCBE Guidelines on the use of cloud-computing services by lawyers; in the Belgian context, see le code de déontologie de l'avocat.

${ }^{65}$ Karpik, French Lawyers, 235.
} 


\section{Bibliography}

Abbott, Andrew. The System of Professions. Chicago: University of Chicago Press, 1988.

Avocats.be. "Home: Avocats.be." Last modified 2020. https://avocats.be/fr/nos-activités?q=fr.

AXA. "AXA: Główna.” Last modified 2019. https://www.smartlegaldoc.eu.

Barton, Benjamin H. "A Glass Half Full Look at the Changes in the American Legal Market." International Review of Law and Economics 38 (2014): 29-42. https://doi.org/10.1016/j.irle.2013.04.010.

Bigda, Jordan. "The Legal Profession: From Humans to Robots." Journal of High Technology Law 18, no 2 (2018): 396-428.

Bosman, Jaap and Lisa Hakanson. Death of a Law Firm: Staying Strong in the Global Legal Market. Washington: American Bar Association, 2017.

Bréchet, Jean-Pierre and Lionel Prouteau. "À la recherche de l'entrepreneur. Au-delà du Modèle Du Choix Rationnel: Une figure de l'agir projectif." Revue Française de Socio-Économie 6, no 2 (2010): 109-130. https://doi.org/10.3917/rfse.006.0109.

Carlson, Matt and Nikki Usher. "News Startups as Agents of Innovation: For-profit Digital News Startup Manifestos as Metajournalistic Discourse.” Digital Journalism 4, no 5 (2016): 563-581. https://doi.org/10.1080/21670811.2015.1076344.

Chishti, Susanne. The LegalTech Book: The Legal Technology Handbook for Investors, Entrepreneurs and FinTech Visionaries. Chichester: John Wiley \& Sons, 2020.

Constitutional Court of Belgium. "Grondwettelijk Hof: Cour Constitutionnelle." Last modified 2020. www.const-court.be.

Corrales Compagnucci, Marcelo, Mark Fenwick, Helena Haapio, and Erik P. M. Vermeulen. "Tomorrow's Lawyer Today? Platform-driven LegalTech, Smart Contracts and the New World of Legal Design.” Journal of Internet Law 22, no 10 (2019): 3-12.

Council of Bars and Law Societies of Europe. CCBE Guidelines on the Use of Cloud Computing Services by Lawyers. (Brussels: Council of Bars and Law Societies of Europe, 2012).

Court of Justice of the European Union. "CURIA." Last modified 2020. http://curia.europa.eu.

Crozier, Michel and Erhard Friedberg. Actors and Systems: The Politics of Collective Action. Chicago: Chicago University Press, 1980.

Dubois, Christophe. "Prison Governors as Policymakers, Phronetic Practices as Enacted Knowledge." The Howard Journal of Crime and Justice 57, no 3 (2018): 363-378. https://doi.org/10.1111/hojo.12255.

Dubois, Christophe and Frédéric Schoenaers. "Les algorithmes dans le droit: Illusions et (r)évolutions. Présentation du dossier." Droit et Société 103, no 3 (2019): 501-515. https://doi.org/10.3917/drs1.103.0501.

Dubois, Christophe, Valérie Mansvelt, and Pierre Delvenne. "Entre nécessité et opportunités: La digitalisation de la justice belge par l'ordre des avocats. " Droit et société 103, no 3 (2019): 555-572. https://doi.org/10.3917/drs1.103.0555.

Freeman, Richard and Steve Sturdy, eds. Knowledge in Policy: Embodied, Inscribed, Enacted. Bristol: Policy Press, 2014.

Friedberg, Erhard. Local Orders: The Dynamics of Organized Action. Greenwich: Jai Press, 1997.

Giraudeau, Martin. "Le travail entrepreneurial, ou l'entrepreneur schumpetérien performé." Sociologie Du Travail 49, no 3 (2007): 330-350. https://doi.org/10.1016/j.soctra.2007.06.025.

Giraudeau, Martin and Frédéric Graber. "Le seuil de l'action. La décision préalable dans l'histoire des projets." Entreprises et Histoire 97, no 4 (2019): 40-57. https://doi.org/10.3917/eh.097.0040.

Incubateur. "The Legal Startups Incubator." Last modified 2020. https://incubateur-ibp.com.

Institut Montaigne, Justice numérique: faites entrer l'accusé. (Institut Montaigne, 2017).

Jean Marot Lawyers. "JM-A Avocats Huy.” Last modified 2020. https://jm-a.be.

Joas, Hans. The Creativity of Action. Oxford: Polity Press, 1996.

Jones, Lauren Joy and Ashley Pearson. "The Use of Technology by Gold Coast Legal Practitioners." Law, Technology and Humans 2, no 1 (2020): 57-74. https://doi.org/10.5204/lthj.v2i1.1304.

Jong, Nathalie de. "Etat des lieux des LegalTech en France." La Semaine Juridique, no 44-45 (2019): 31-36.

Karpik, Lucien. French Lawyers: A Study in Collective Action, 1274 to 1994. Oxford: Oxford University Press, 1999.

Kobayashi, Bruce H. "Law's Information Revolution as Procedural Reform." University of Illinois Law Review, no 5 (2013): 1473-1516. https://doi.org/10.2139/ssrn.2340068.

Kuty, Olgierd and Christophe Dubois. De la valeur à la norme: Introduction à la sociologie. Louvain-la-Neuve: De Boeck Supérieur, 2019.

Latour, Bruno. Aramis, or the Love of Technology. Cambridge: Harvard University Press, 1996.

Lawbox. "Authors." Last modified 2020. https://www.lawbox.be/plus/auteurs.

_. "Home: Lawbox." Last modified 2020. https://www.lawbox.be.

"Prices." Last modified 2020. https://www.lawbox.be/tarif.

Lawbox Colocation. "Home: Lawbox." Last modified 2018. https://www.pactecoloc.be.

LawboxPRO. "Home: LawboxPRO.” Last modified 2019. https://lawboxpro.com.

Lawgitech. "Home: Lawgitech.” Last modified 2020. http://www.lawgitech.eu. 
“Lawgitech Design.” Last modified 2020. http://www.lawgitech.eu/lawgitechfr/lawgitechdesign.html.

Legal Street. "Home: Legal Street." Last modified 2020. https://www.legalstreet.be.

Legal Tech. "Home: Legal Tech.” Last modified 2019. https://www.legaltechcongres.be/.

Lentsiou, Elisabetta, Dimitrios Valsamidis, Dimitra Giannopoulou, Kalliopi Kalampouka, and Lambros Tsourgiannis. "Do the New Business Models Provide 'Justice' to Legal Services?” Journal of Business in The Digital Age 1, no 1 (2018): $22-32$.

Lex4u. "Home: Lex4u." Last modified 2020. http://www.lex4u.com.

L’Incubateur. "Incubateur Avocats.be." Last modified 2020. http://www.incubateur.legal/.

Nambisan, Satish, Donald Siegel, and Martin Kenney. "On Open Innovation, Platforms, and Entrepreneurship." Strategic Entrepreneurship Journal 12, no 3 (2018): 354-368. https://doi.org/10.1002/sej.1300.

Online Solution Attorney. “Create Your Lawyer Account.” Last modified 2020. https://onlinesolutionattorney.be/en/Account/RegisterAttorney.

—_. "How it Works." Last modified 2020. https://onlinesolutionattorney.be/en/HowItWorks.

"Services Juridiques en Ligne.” Last modified 2020. https://onlinesolutionattorney.be.

Orlikowski, Wanda J. "Sociomaterial Practices: Exploring Technology at Work." Organization Studies 28, no 9 (2007): 1435-1448. https://doi.org/10.1177/0170840607081138.

Partena Professional. "Home: Partena Professional.” Last modified 2019. https://legalsmart.partena-professional.be.

Pivovarov, Valentin. “713\% Growth: LegalTech Set an Investment Record in 2018.” Forbes, January 15, 2019. https://www.forbes.com/sites/valentinpivovarov/2019/01/15/legaltechinvestment2018/\#2b5a0e707c2b.

Reshape Legal. "Legal and Tech Summit." Last modified 2020. https://www.reshape.legal/legal-tech-summit-312389.html.

Reynaud, Jean-Daniel. Les règles du jeu: L'action collective et la régulation sociale. Paris: Armand Colin, 1989.

Rhattat, Rachid. 'L'incubateur du Barreau de Paris: Un dispositif d'accompagnement entrepreneurial dédié à l'innovation juridique." Entreprendre and Innover 40, no 1 (2019): 55-64. https://doi.org/10.3917/entin.040.0055.

Ribstein, Larry E. "Delawyering the Corporation." Wisconsin Law Review 2012, no 2 (2012): 305-332. https://doi.org/10.2139/ssrn.1970376.

Schwab, Klaus. The Fourth Industrial Revolution. New York: Crown Business, 2017.

Simon, Herbert A. "Bounded Rationality in Social Science: Today and Tomorrow." Mind and Society 1, no 1 (2000): $25-39$. https://doi.org/10.1007/BF02512227.

Skjolsvik, Tale, Karl J. Breunig, and Frida Pemer. "Digitalization of Professional Services: The Case of Value Creation in Virtual Law Firms.” In Managing Digital Transformation, edited by Per Andersson, Staffan Movin, Magnus Mähring, and Robin Teigland, 155-174. Stockholm: SIR, 2018.

Stanford Law School, "2019 Statistics." 2020. http://techindex.law.stanford.edu/statistics?founded date=2019. . "CodeX Techindex." 2020. http://techindex.law.stanford.edu.

Susskind, Richard. The End of Lawyers: Rethinking the Nature of Legal Services. Oxford: Oxford University Press, 2010. Tomorrow's Lawyers: An Introduction to Your Future. Oxford: Oxford University Press, 2017.

Thomson Reuters and Legal Geek. LegalTech Startup Report 2019: A Maturing Market. (Thomson Reuters, October, 2019).

Thornton, Margaret. "Towards the Uberisation of Legal Practice." Law, Technology and Humans 1, no 1 (2019): $46-63$. https://doi.org/10.5204/lthj.v1i1.1277.

Village de la Justice. "[Exclusive] Guide and Permanent Observatory of LegalTech and Law Start-ups.” Last modified March 23, 2020. https://www.village-justice.com/articles/spip.php?page=imprimer\&id_article=18224.

Wassenhove, Stanislas van. Livre Blanc guide de la LegalTech en Belgique. Bruxelles: Larcier, 2019.

Wassenhove, Stanislas van and Adrien van den Branden. "Free Digital Training in Bars!" La Tribune (blog). Avocats.be, July 2019. https://latribune.avocats.be/une-formation-gratuite-au-digital-dans-les-barreaux/.

Webley, Lisa, John Flood, Julian Webb, Francesca Bartlett, Kate Galloway, and Kieran Tranter. "The Profession(s)' Engagements with LawTech: Narratives and Archetypes of Future Law.” Law, Technology and Humans 1, no 1 (2019): 6-26. https://doi.org/10.5204/lthj.v1i0.1314.

Yoo, Youngjin, Richard J. Boland, Kalle Lyytinen, and Ann Majchrzak. "Organizing for Innovation in the Digitized World." Organization Science 23, no 5 (2012): 1398-1408. https://doi.org/10.1287/orsc.1120.0771. 